Article

\title{
A Combination of PROBA-V/MODIS-Based Products with Sentinel-1 SAR Data for Detecting Wet and Dry Snow Cover in Mountainous Areas
}

\author{
Ya-Lun S. Tsai ${ }^{1, * \mathbb{C}}$, Andreas Dietz ${ }^{1}$, Natascha Oppelt ${ }^{2} \mathbb{D}$ and Claudia Kuenzer ${ }^{1}$ \\ 1 German Remote Sensing Data Center (DFD), German Aerospace Center (DLR), Muenchener Strasse 20, \\ D-82234 Wessling, Germany \\ 2 Department of Geography, Earth Observation and Modelling, Kiel University, Ludewig-Meyn-Str. 14, \\ 24118 Kiel, Germany \\ * Correspondence: Ya-Lun.Tsai@dlr.de
}

Received: 24 June 2019; Accepted: 13 August 2019; Published: 14 August 2019

\begin{abstract}
In the present study, we explore the value of employing both vegetation indexes as well as land surface temperature derived from Project for On-Board Autonomy-Vegetation (PROBA-V) and Moderate Resolution Imaging Spectroradiometer (MODIS) sensors, respectively, to support the detection of total (wet + dry) snow cover extent (SCE) based on a simple tuning machine learning approach and provide reliability maps for further analysis. We utilize Sentinel-1-based synthetic aperture radar (SAR) observations, including backscatter coefficient, interferometric coherence, and polarimetric parameters, and four topographical factors as well as vegetation and temperature information to detect the total SCE with a land cover-dependent random forest-based approach. Our results show that the overall accuracy and F-measure are over $90 \%$ with an 'Area Under the receiver operating characteristic Curve (ROC)' (AUC) score of approximately 80\% over five study areas located in different mountain ranges, continents, and hemispheres. These accuracies are also confirmed by a comprehensive validation approach with different data sources, attesting the robustness and global transferability. Additionally, based on the reliability maps, we find an inversely proportional relationship between classification reliability and vegetation density. In conclusion, comparing to a previous study only utilizing SAR-based observations, the method proposed in the present study provides a complementary approach to achieve a higher total SCE mapping accuracy while maintaining global applicability with reliable accuracy and corresponding uncertainty information.
\end{abstract}

Keywords: Synthetic aperture radar; InSAR; PolSAR; backscatter; machine learning; snow cover area; land use land cover; Sentinel-2; Landsat

\section{Introduction}

Global warming leads to a significant decrease in snow cover extent (SCE) as proven in both observations and models [1,2]. This development has also been recorded in the Synthesis Report of the Fifth Assessment Report (AR5) of the Intergovernmental Panel on Climate Change (IPCC) [3]. As SCE is an important factor for various human activities as well as the natural environment, a decrease in SCE affects and deteriorates the balance of ecosystems, the hydrological cycle of major river catchments, and the global radiation budget. The latest IPCC special report of 2018 states that extreme SCE changes could affect winter tourism and hydrology [4]. In addition, several studies suggest that runoff generated by snowmelt dominates not only the amount but also the distribution, quality, and seasonality of its downstream regions [5-7] and that it further controls water resources of whole populations [8]. Moreover, snow would also interact with other cryospheric components such as the equilibrium of 
glaciers [9], the active layer thickness of permafrost [10], and the retention of sea and lake ice [11]. Hence, a continuous monitoring strategy for SCE is necessary.

Although there have been various spaceborne multispectral sensor-based SCE products, such as the Moderate Resolution Imaging Spectroradiometer (MODIS)-based snow cover products [12] and the European Space Agency (ESA)'s GlobSnow product [13], these are still fundamentally constrained by cloud coverage, polar darkness, and the confusion between snow and ice clouds [14,15]. Thus, the utilization of active synthetic aperture radar (SAR) has been explored in the recent three decades (for a comprehensive review we refer to Tsai et al. (2019) [16]). Thanks to its longer wavelength, SAR can sense ground features under all weather and solar illumination conditions. Since the first pioneer study published by Nagler and Rott in 2000 [17], various studies have been conducted utilizing the backscatter information to detect wet SCE. This is based on the fact that once the snow becomes wet, the dielectric constant of the snowpack increases significantly, leading to a dramatic shortening of the penetration depth of SAR signals [16]. This behavior can be exploited to detect wet snow, relying on a backscatter threshold-based approach. Dry SCE, however, cannot be detected by this approach alone. Because information about the total (wet + dry) SCE is critical for further applications (e.g., hydrological modeling), interferometric SAR (InSAR) as well as polarimetric SAR (PolSAR) have been investigated [18]. InSAR coherence enables total SCE mapping based on the fact that the snow-covered areas would show lower coherence due to a change in the SAR signal penetration depth [19], and PolSAR decomposed parameters enable dry/wet/total SCE mapping as they can reveal the scattering mechanism of different ground features [20]. For a detailed discussion and comparison of three mainstream SAR-based SCE detection approaches, we refer to Tsai et al. [16].

An important tool in detecting SCE relying on SAR data are machine learning (ML) techniques. Thanks to their strengths in dealing with massive data, they allow for a full exploitation of the PolSAR and InSAR parameters, as well as a combination with the conventional (often noisy) backscatter values. Although, so far, there have been some ML-based SCE mapping studies [21-23], they only utilized Support Vector Machines (SVMs) for classification, which was relatively challenging to tune, and to handle the data [24-26]. Hence, a universally applicable and straightforward ML approach needed to be explored. Furthermore, most of the studies only tested their SAR-based total SCE detection algorithms at a local scale without proper validation, and often masked out the forested and agricultural regions to avoid vegetation-caused classification ambiguities $[16,23,27,28]$. Therefore, these algorithms might be site-dependent and not globally transferable.

In a previous study [18], we proposed a globally transferable, freely accessible data-only, all land cover class-applicable total and wet SCE mapping strategy utilizing only SAR-based observations (backscattering, InSAR coherence, and PolSAR parameters) as well as topographical factors. Based on a comprehensive validation approach, an overall accuracy of approximately $80 \%$ was confirmed. Although this accuracy level is already much higher than those of previous SAR-based studies [16], it is still relatively low when compare to conventional, optical sensor-based SCE detection approaches. Thus, a further enhancement of the mapping accuracy is desirable. To improve the SCE mapping accuracy, previous studies commonly employed ground temperature information derived from passive microwave sensors [29-31], as the snow-covered regions would show a lower temperature when compared to other, snow free regions. In addition to the temperature information, vegetation indexes might also help to detect SCE especially in forested regions. In a previous study, we found [18] that the densely vegetated regions tend to show lower SCE mapping accuracy when compared to, e.g., bare area, sparse vegetation, and grassland. Moreover, previous studies also suggested that SAR backscatter, InSAR coherence, and PolSAR parameters are all related to vegetation types and conditions [23,32-34]. Therefore, quantitative vegetation information should be added in addition to the qualitative vegetation information we already include (i.e., land cover map). Consequently, in the present study, we explore the value of including Project for On-Board Autonomy-Vegetation (PROBA-V)/MODIS-based vegetation and surface temperature products for enhancing the total SCE mapping accuracy. Also, since no procedure exists that provides a reliability map along with the 
estimated SCE, the present study also includes a workflow for an automatically generated reliability map. Summarized, the following objectives have been addressed in this study: (1) the enhancement of the mapping accuracy of total SCE by including vegetation indexes and temperature information, (2) the provision of reliability maps along with the modeled total SCE for further analysis, and (3) the analysis of the influence of land cover classes with different vegetation densities on the total SCE mapping reliability.

\section{Study Areas and Dataset}

\subsection{Study Areas}

To test the transferability of our method, we selected five study areas located at different major mountainous regions around the globe with different land cover and topography, including the European Alps (Monte Rosa, (MR) and Zugspitze (ZG)), Sierra Nevada (Mount Whitney (MW)), Himalaya (Langtang Lirung (LL)), and Southern Alps in New Zealand (Aoraki (AK)). The locations and characteristics of each region are represented in Table 1.

Table 1. Attributes of the five selected study areas including Monte Rosa (MR), Zugspitze (ZG), Mount Whitney (MW), Landtang Lirung (LL), and Aoraki (AK) with their location, mountain range, country, and the highest peak.

\begin{tabular}{|c|c|c|c|c|c|}
\hline Testing Sites & 1 (MR) & $2(\mathrm{ZG})$ & 3 (MW) & $4(\mathrm{LL})$ & 6 (AK) \\
\hline Continent & Europe & Europe & North America & Asia & Australia \\
\hline $\begin{array}{l}\text { Mountain } \\
\text { Range } \\
\text { (Country) }\end{array}$ & $\begin{array}{c}\text { Alps } \\
\text { (Switzerland) }\end{array}$ & $\begin{array}{c}\text { Alps } \\
\text { (Germany) }\end{array}$ & $\begin{array}{c}\text { Sierra Nevada } \\
\text { (U.S.A.) }\end{array}$ & $\begin{array}{l}\text { Himalaya } \\
\text { (Nepal) }\end{array}$ & $\begin{array}{l}\text { Southern Alps } \\
\text { (New Zealand) }\end{array}$ \\
\hline $\begin{array}{l}\text { Highest Peaks } \\
\text { (Height) }\end{array}$ & $\begin{array}{c}\text { Monte Rosa } \\
(4634 \mathrm{~m})\end{array}$ & $\begin{array}{l}\text { Zugspitze } \\
(2962 \mathrm{~m})\end{array}$ & $\begin{array}{l}\text { Mount Whitney } \\
\quad(4421 \mathrm{~m})\end{array}$ & $\begin{array}{l}\text { Langtang } \\
\text { Lirung } \\
(7234 \mathrm{~m})\end{array}$ & $\begin{array}{c}\text { Aoraki/Mount } \\
\text { Cook } \\
(3724 \mathrm{~m})\end{array}$ \\
\hline
\end{tabular}

\section{2. $S A R$ and Optical Imagery}

As we utilized a supervised classification approach, two consecutive hydrological years were chosen, with first- and second-year Sentinel-1 SAR imagery used as a training and validation set, respectively. For the training set, SAR images of three different months, representing different snow cover conditions, were selected as shown in Table 2. Also, we included two different months (Month1: month not included in training set; Month2: month included in training set) for mapping to exclude the possibility that the selection of only a single month might influence the classification accuracy. Additionally, as the snowpack and its structure are changing continuously throughout the season, selecting different months ensures that the developed method will work under different snowpack conditions. For validating the SAR-based total SCE, optical imagery recorded during the validation year was also employed. To ensure the reliability of the validation, optical scenes from Sentinel-2 and Landsat-7/8 containing minimum cloud coverage were chosen that were recorded at similar dates as the respective Sentinel-1 imagery. Hence, the temporal gap between SAR and optical imagery for all cases is within a week. The summary of the employed SAR and optical imagery for each test site is listed in Table 2. 
Table 2. Summary of the synthetic aperture radar (SAR) data (Sentinel-1) and optical data (Sentinel-2, S2; Landsat-7/8, L7/8) used in the training and validation set. Note: the reference image of each region for calculating the wet snow cover extent (SCE) is marked with an asterisk $\left(^{*}\right)$; optical images employed in the validation set are included in brackets below the used SAR image dates.

\begin{tabular}{|c|c|c|c|}
\hline \multirow[b]{2}{*}{ Region } & \multirow{2}{*}{$\begin{array}{c}\text { Training Set } \\
\text { (First Hydrological Year) } \\
\text { * Reference Image }\end{array}$} & \multicolumn{2}{|c|}{$\begin{array}{c}\text { Validation Set } \\
\text { (Second Hydrological Year) }\end{array}$} \\
\hline & & $\begin{array}{c}\text { Month1 } \\
\text { (Month not Included } \\
\text { in Training Set) }\end{array}$ & $\begin{array}{l}\text { Month2 } \\
\text { (Month Included } \\
\text { in Training Set) }\end{array}$ \\
\hline $\begin{array}{l}\text { Test Site 1: Monte Rosa (MR) } \\
\text { (Sentinel-1A, Ascending, } \\
\text { relative orbit number: } 88 \text { ) } \\
\text { (Landsat-7/8, path: 195, row: } 28 \text { ) }\end{array}$ & $\begin{array}{c}\text { 17-29 November } 2016 \\
\text { 9-21 February } 2017 \\
\text { 16-28 May } 2017 \\
\text { * } 8 \text { August } 2017\end{array}$ & $\begin{array}{l}\text { 24 March- } \\
5 \text { April } 2018 \\
\text { (L7: } 23 \text { March) }\end{array}$ & $\begin{array}{l}23 \text { May- } \\
4 \text { June } 2018 \\
\text { (L8: } 18 \text { May) }\end{array}$ \\
\hline $\begin{array}{l}\text { Test Site 2: Zugspitze (ZG) } \\
\text { (Sentinel-1A, Ascending, } \\
\text { relative orbit number: } 117 \text { ) } \\
\text { (Landsat-7, path: } 193, \text { row: } 27 \text { ) } \\
\text { (Sentinel-2, tile number: T32TPT) }\end{array}$ & $\begin{array}{c}\text { 7-19 November } 2016 \\
\text { 23 February- } \\
7 \text { March } 2017 \\
\text { 18-30 May } 2017 \\
\text { * 10 August } 2017\end{array}$ & $\begin{array}{c}\text { 26 March- } \\
7 \text { April } 2018 \\
\text { (L7: } 25 \text { March) }\end{array}$ & $\begin{array}{l}\text { 13-25 May } 2018 \\
\quad(S 2: 7 \text { May) }\end{array}$ \\
\hline $\begin{array}{l}\text { Test Site 3: Mount Whitney (MW) } \\
\text { (Sentinel-1A, Ascending, } \\
\text { relative orbit number: } 144 \text { ) } \\
\text { (Landsat-7, path: } 41, \text { row: } 35)\end{array}$ & $\begin{array}{c}25 \text { February- } \\
9 \text { March } 2017 \\
\text { 2-14 April } 2017 \\
\text { 8-20 May } 2017 \\
\text { * } 12 \text { August } 2017\end{array}$ & $\begin{array}{l}\text { 16-28 March } 2018 \\
\text { (L7: 16 March) }\end{array}$ & $\begin{array}{l}\text { 3-15 May } 2018 \\
\text { (L7: } 3 \text { May) }\end{array}$ \\
\hline $\begin{array}{l}\text { Test Site 4: Landtang Lirung (LL) } \\
\text { (Sentinel-1A, Ascending, } \\
\text { relative orbit number: } 85 \text { ) } \\
\text { (Landsat-7, path: } 141, \text { row: } 40 \text { ) }\end{array}$ & $\begin{array}{l}\text { 9-21 February } 2017 \\
\text { 10-22 April } 2017 \\
\text { 16-28 May } 2017 \\
\text { * 8 August } 2017\end{array}$ & $\begin{array}{l}\text { 12-24 March } 2018 \\
\text { (L7: } 13 \text { March) }\end{array}$ & $\begin{array}{l}\text { 11-23 May } 2018 \\
\text { (L7: } 16 \text { May) }\end{array}$ \\
\hline $\begin{array}{l}\text { Test Site 5: Aoraki (AK) } \\
\text { (Sentinel-1B, Ascending, } \\
\text { relative orbit number: } 23 \text { ) } \\
\text { (Landsat-7/8, path: } 75, \text { row: } 90 \text { ) }\end{array}$ & $\begin{array}{c}\text { 6-18 May } 2017 \\
\text { 10-22 August } 2017 \\
21 \text { October-2 November } 2017 \\
\text { *6 February } 2018\end{array}$ & $\begin{array}{l}30 \text { June-- } \\
\text { 12 July } 2018 \\
\text { (L8: } 26 \text { June) }\end{array}$ & $\begin{array}{l}\text { 1-13 May } 2018 \\
\text { (L7: } 1 \text { May) }\end{array}$ \\
\hline
\end{tabular}

\subsection{Auxiliary Data}

Due to the trade-offs between global availability, sustainability, and data quality, the National Aeronautics and Space Administration (NASA)'s Shuttle Radar Topographic Mission (SRTM) digital elevation model (DEM) as well as land cover data originating from the ESA Climate Change Initiative (CCI) were used as auxiliary data. The former was employed to calculate the topographical factors (elevation, slope, aspect, and curvature). The CCI land cover product was reclassified from 37 to 16 classes to reduce redundancy [18]. The daily and global SCE derived from DLR's Global SnowPack (GSP) [35] was employed as ground truth for training the model, which has been validated using in situ and higher resolution reference data for an accuracy of approximately $80 \%$ globally [35].

In the present paper, to enhance the SCE mapping accuracy, two vegetation indexes as well as surface temperature derived from the PROBA-V satellite and MODIS sensors, respectively, were also employed. The vegetation index products including leaf area index (LAI) and fractional vegetation cover (FVC) are provided by the Copernicus Global Land Service and are calculated based on three PROBA-V bands (blue, red, and near-infrared) [36]. It must be noted that a correlation between LAI and FVC might exist. However, as the classification algorithm we employed (random forest) is capable of dealing with collinearity between features and the goal of our approach is to provide a universally applicable model which can yield the highest classification accuracy, we do not consider this a problem. A possible redundancy between input variables is acceptable for ensuring flexibility.

The surface temperature is based on merging both Terra and Aqua satellite data of MODIS Level-3 8-day composite products (MOD/MYD11A2), which are averaged from clear-sky daily products (MOD/MYD11A1) based on MODIS's band 31 and 32 emissivities [37,38]. MOD/MYD11B1 and MOD/MYD11C1 were not selected because they are resampled to a much coarser resolution $(6 \mathrm{~km}$ and $0.05^{\circ}$, respectively), making them more applicable for global analysis or climate modelling applications [38-40]. We selected the composite product instead of daily products because (1) the revisit time of Sentinel-1 SAR (12 days) is comparable with MOD/MYD11A2's 8-day period and (2) more 
complete spatial data availability can be achieved. Together with the SAR-based observations and topographical factors, the data types, sources, and spatial/temporal resolution of the data employed in the present study are listed in Table 3.

Table 3. Attributes of input data with their source, spatial and temporal resolution. National Aeronautics and Space Administration (NASA)'s Shuttle Radar Topographic Mission, Moderate Resolution Imaging Spectroradiometer, and Project for On-Board Autonomy-Vegetation are abbreviated as SRTM, MODIS, and PROBA-V, respectively.

\begin{tabular}{|c|c|c|c|c|}
\hline Input Variable & Data Category & Source & $\begin{array}{c}\text { Spatial } \\
\text { Resolution }\end{array}$ & $\begin{array}{c}\text { Temporal } \\
\text { Resolution }\end{array}$ \\
\hline Total SCE & Ground truth & Global SnowPack & $500 \mathrm{~m}$ & Daily \\
\hline Land cover & Land cover label & $\begin{array}{l}\text { European Space Agency } \\
\text { (ESA) Climate Change } \\
\text { Initiative (CCI) land cover }\end{array}$ & $300 \mathrm{~m}$ & Annually \\
\hline $\begin{array}{c}\text { Backscattering coefficient } \\
\text { Interferometric SAR } \\
\text { (InSAR) coherence } \\
\text { Polarimetric SAR (PolSAR) entropy } \\
\text { PolSAR anisotropy } \\
\text { PolSAR angle }\end{array}$ & SAR observation & $\begin{array}{l}\text { SAR image processing } \\
\text { (Sentinel-1) }\end{array}$ & $5 \times 20 \mathrm{~m}$ & 12 days \\
\hline $\begin{array}{c}\text { Elevation } \\
\text { Slope } \\
\text { Aspect } \\
\text { Curvature }\end{array}$ & $\begin{array}{l}\text { Topographical } \\
\text { factor }\end{array}$ & $\begin{array}{c}\text { SRTM digital elevation } \\
\text { model (DEM) }\end{array}$ & $90 \mathrm{~m}$ & N/A \\
\hline $\begin{array}{l}\text { Leaf area index } \\
\text { Fractional vegetation cover }\end{array}$ & Vegetation index & $\begin{array}{l}\text { Copernicus Global Land } \\
\text { Service (PROBA-V based) }\end{array}$ & $300 \mathrm{~m}$ & 10 days \\
\hline Land surface temperature & Temperature & $\begin{array}{l}\text { MOD/MYD11A2 } \\
\text { (MODIS based) }\end{array}$ & $1000 \mathrm{~m}$ & 8 days \\
\hline
\end{tabular}

\section{Methodology}

For calculating the SAR-based observations, including the backscatter ratio, InSAR coherence, and PolSAR H/A/ $\alpha$ parameters, Sentinel-1 imagery was processed with ESA's SentiNel Application Platform (SNAP). To derive the backscatter ratio, Ground-Range Detected (GRD) images were calibrated, filtered, terrain corrected and flattened with SRTM DEM, and finally converted to decibel (dB) units. Each image was set in relation to a reference image originating from summer season. InSAR coherence was derived from two co-registered Single-Look Complex (SLC) images, which were then terrain corrected and filtered. For PolSAR parameters, the polarimetric matrix was first constructed from the calibrated and debursted SLC images and the derived eigenvalues and eigenvectors were then used for calculating $\mathrm{H} / \mathrm{A} / \alpha$ parameters [20]. For a more detailed description of the SAR pre-processing, we refer to Tsai et al. (2019) [18].

Random forest (RF) was employed in the present study as a two-class supervised classifier owing to its simplicity of parameter tuning. It guarantees a wider applicability than algorithms such as SVM and neural network. Moreover, RF provides other benefits including a short training time, low computation load, support of parallel processing, simple tuning of parameters, avoiding of over-fitting, and providing information about the importance of the input variables [41-43]. Regarding the parameter setting, the numbers of trees and the number of random features assigned to each tree, they were set to 600 and the default values (square root of total feature numbers) after several testing trials [18], respectively. For building the RF model, different input combinations (inputs are listed in Table 3) were tested. After finding the optimized combination, the model was applied to each land cover class individually. Accordingly, each modeling trial for each study area consists of $N$ RF models, with $N$ referring to the number of land cover classes. We processed the input data for two distinct scenarios: (1) single-area scenario: each region's first-year data was used to build the model for each region individually, which were then correspondingly applied to the region's second-year 
data; (2) merging-region scenario: the input data of all test regions were merged for the first year to build one aggregated model, which was then applied to the second year.

To build the models, 70\% of the pixels of the first-year data (including GSP data as ground truth and the selected inputs from Table 3) were randomly selected and used to train the model. The trained model was then used to estimate total SCE, which was validated with internal (30\% of the first-year GSP data, not included in the training process) and external data (optical-based SCE data and snow depth station data). An extensive description of the data splitting is presented in Tsai et al. (2019) [18]. To evaluate the performance of the different input and model settings, overall accuracy, F-measure [44], and 'Area Under the ROC' (receiver operating characteristic curve) (AUC) [45] were calculated, which provide a comprehensive evaluation $[46,47]$. To examine the negative effect of vegetation on the classification accuracy, these measurements were also calculated separately for non-forested regions.

To select the optimized input combinations and evaluate the benefits of adding vegetation indexes and surface temperature information in addition to SAR-based observations and topographical factors employed in [18], the Monte Rosa (MR) region in the Swiss Alps was chosen for accuracy assessment, as it features complex land cover and topography. To assess the robustness of the model, 20 iterations were processed for each trial. The results of the different classification accuracies are illustrated in Figure 1. It was found that adding both vegetation indexes and temperature information can yield the highest accuracy: Overall accuracy and F-measure can reach around 93\% accuracy, with an AUC score of approximately $84 \%$. The original SAR-based (BIP) and topographical factors (asce)-based approach without vegetation and temperature information produced only 82 and 70\% accuracy, respectively [18].

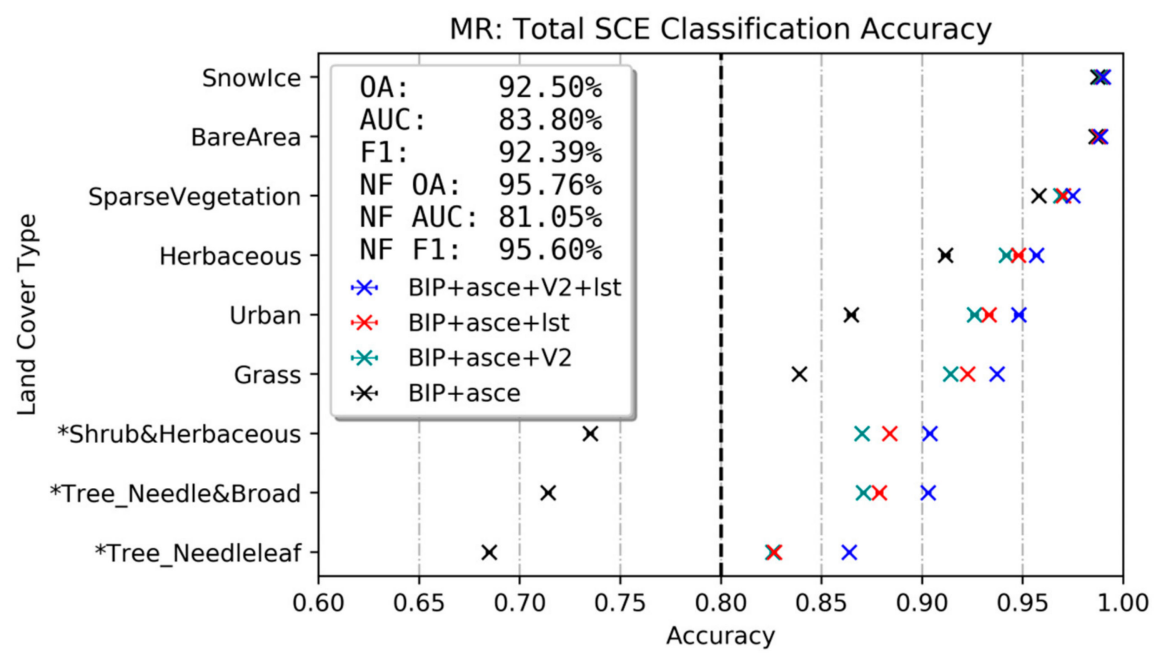

Figure 1. Assessment of the influence of different input combinations on the performance of the model for the Monte Rosa (MR) region. Different classification accuracies based on different input combinations are marked in different colors, and the accuracy for each land cover class is marked in the same horizontal axis. SAR-based observations, including backscatter, interferometric SAR (InSAR) coherence, and polarimetric (PolSAR) H/A/ $\alpha$ parameters are abbreviated as $\mathrm{B}$, I, and $\mathrm{P}$, respectively. Topographical factors, including aspect, slope, curvature, and elevation are abbreviated as a, s, c, and e, respectively. Two vegetation indexes and land surface temperature are abbreviated as V2 and lst, respectively. Non-forest classes' overall accuracy, F measure, and area under the receiver operating characteristic curve are abbreviated as NF OA, NF F1, and NF AUC, respectively.

The increase in overall classification accuracy is largely due to improvements in regions covered by forests. For the mixed needle and broadleaf tree class, the original SAR-based (BIP) and topographical factors (asce) approach achieves an overall accuracy of approximately $71 \%$. After including the vegetation indexes and temperature information, the accuracy increases to approximately $87 \%$. This demonstrates the benefit of including not only qualitative vegetation information (i.e., land cover map) but also quantitative vegetation information. This finding agrees with previous studies which 
revealed that SAR signals would largely relate to the transmissivity of vegetation $[16,33]$ which is correlated to the LAI and FVC [48]. The accuracy improvement achieved by including temperature data is straightforward, as it provides general surface thermal information. The temperature data allows for a differentiation into cold (potentially snow covered) and warm regions (potentially snow-free). Consequently, even though the MODIS-based temperature product has a lower spatial resolution $(1000 \mathrm{~m})$ than the PROBA-V-based medium resolution $(300 \mathrm{~m})$ vegetation indexes, the SCE mapping accuracy for all land cover classes is higher when compared to the benefit gained by including the two vegetation indexes (BIP+asce+V2). A detailed overview is illustrated in Figure 1.

Ultimately, nearly 90\% accuracy can be achieved when all inputs are included. Therefore, all available SAR-based observations, topographical parameters, two vegetation indexes, and temperature information have been used as model inputs for the subsequently presented results. For these results, we do not filter variables based on the importance of variables calculated from RF because (1) the RF's importance metrics are found to be biased when predictor variables vary in scales of measurements or share collinearity [49,50]; and (2) the goal of the proposed approach is to provide universal applicability and a slight redundancy of variables can ensure broader transferability and flexibility.

Based on the RF model sets, the total SCE for each month of each region's validation year can be derived. Additionally, a conventional backscatter-based wet SCE detection approach was also employed [17] to utilize the full potential of the SAR data for discriminating between wet and dry snow. Reference images were selected from the summertime of the first year as shown in Table 2 . The ratio of the backscattering coefficient values between observation and reference SAR images was set to a threshold of $-3 \mathrm{~dB}$ to depict wet SCE. Hence, it became viable to generate holistic dry and wet SCE results based on SAR data. In the present study, both years' SAR backscatter observations were combined with the reference image (summertime observation) of the first year (Table 2), as the feasibility of using a cross-temporal reference image was proven by Luojus et al. (2006) [51].

The overall workflow of mapping total SCE based on a land cover-dependent RF classification model set as well as detecting wet SCE by "Nagler's method" is illustrated in Figure 2.

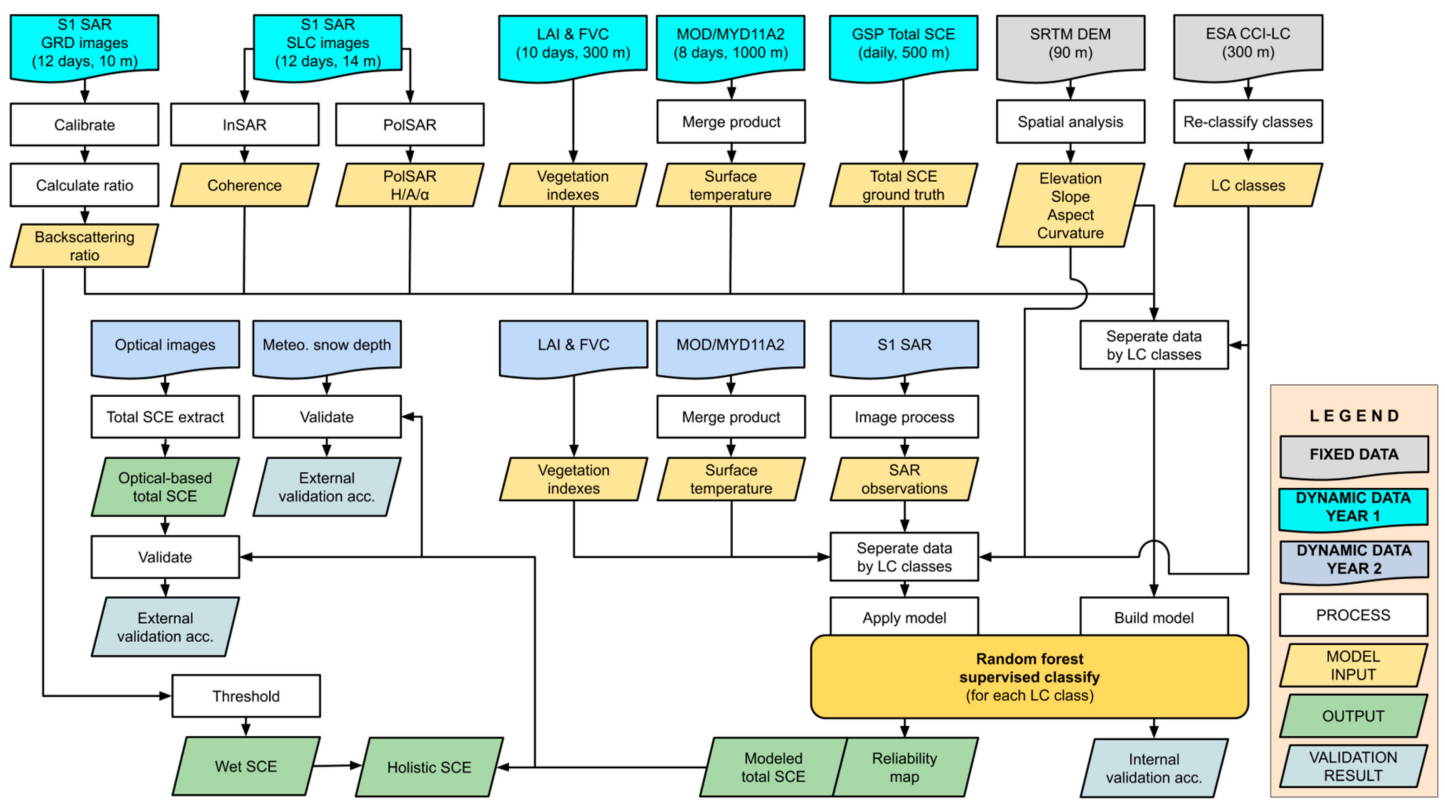

Figure 2. Overall workflow of mapping and validating holistic (total + wet) Snow Cover Extent (SCE) with SAR-based observations, topographical factors, vegetation indexes, temperature information, land cover information, and Global SnowPack (GSP) daily snow cover information. Single-Look Complex, Ground-Range Detected, shuttle radar topographic mission digital elevation model, and land cover are abbreviated as SLC, GRD, SRTM DEM, and LC, respectively. 


\section{Results}

\subsection{Accuracy Assessment of the Modeled Total SCE}

Based on the optimized input variable combinations tested in the Methodology section (SAR-based observations, topographical factors, vegetation indexes, and temperature information), the same modeling approach was applied to all five study areas individually. The resultant internal validation of the first year is shown in Figure 3. To highlight the improved classification accuracy achieved by adding vegetation indexes and temperature information, the results of using only the previous variable combination (BIP + asce) [18] are also plotted. To assess the robustness of the model, 20 iterations were processed for each trial. For the single-area scenario, the total SCE mapping accuracies of all five regions are illustrated in Figure 3a-e. The overall accuracy and F-measure were approximately 93, 90, 96, 93, and 92\% for MR, ZG, MW, LL, and AK, respectively. The AUC score for each region was also over $77 \%$, which is more than satisfying. To compare the negative effect of vegetation on the classification accuracy, the non-forest classes were assed separately (represented in Figure 3 with NF OA, NF AUC, NF F1). The non-forest overall accuracy and F-measure were approximately 96, 93, 99, 89, and 93\% for MR, ZG, MW, LL, and AK, respectively.

(a)

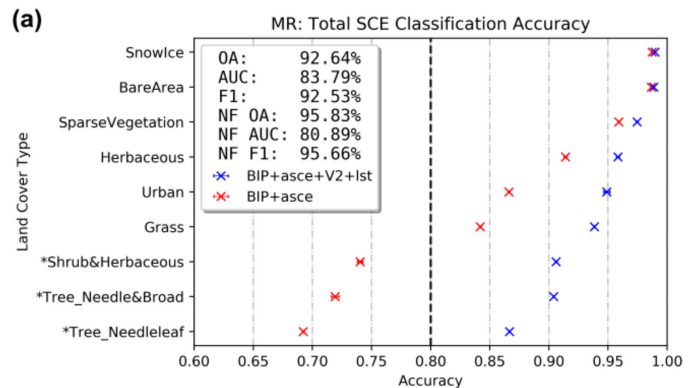

(c)
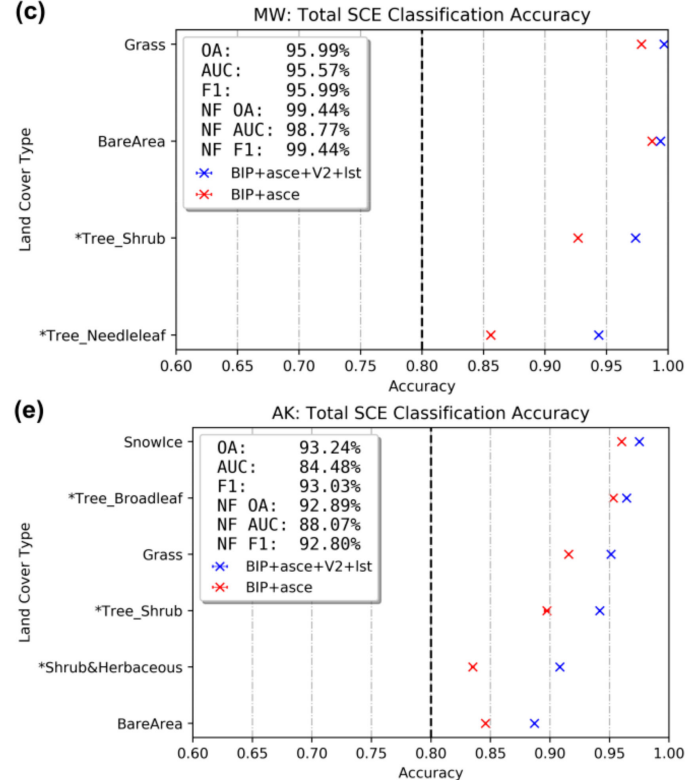

(b)

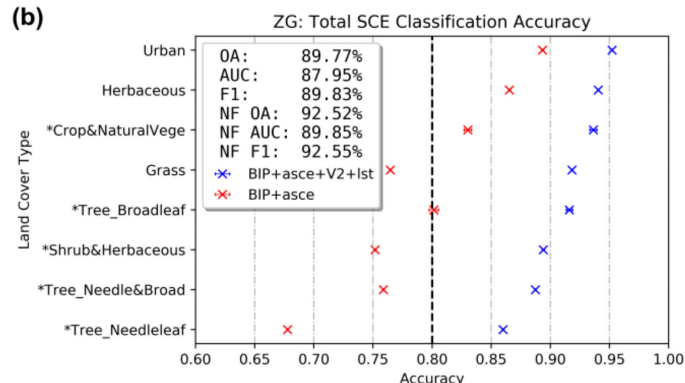

(d)
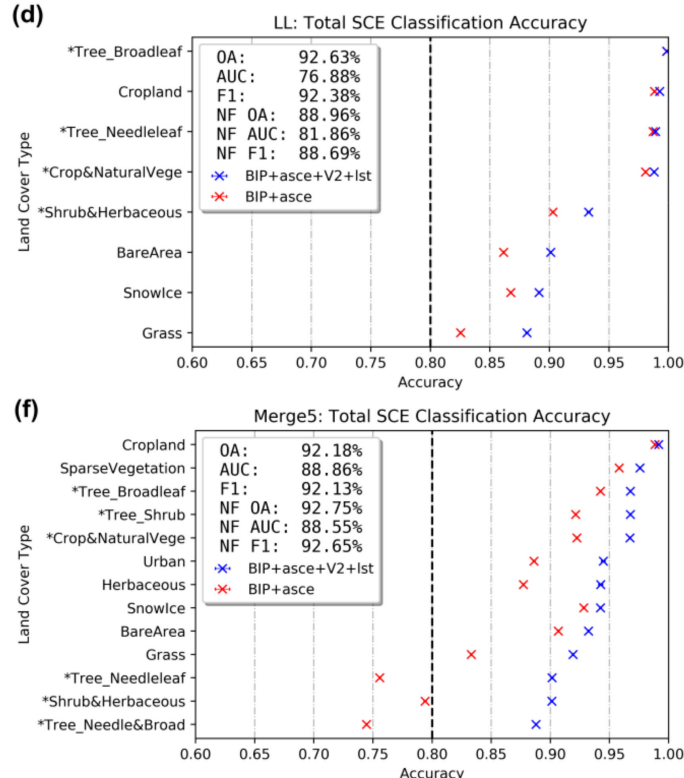

Figure 3. The results of each model set built in each region: (a) Monte Rosa (MR); (b) Zugspitze (ZG); (c) Mount Whitney (MW); (d) Landtang Lirung (LL); and (e) Aoraki (AK); and merging the five regions (f). Different classification accuracies based on different input combinations are marked in different colors, and the accuracy for each land cover class is marked in the same horizontal axis. SAR-based observations, including backscatter, interferometric SAR (InSAR) coherence, and polarimetric (PolSAR) $\mathrm{H} / \mathrm{A} / \alpha$ parameters are abbreviated as B, I, and P, respectively. Topographical factors, including aspect, slope, curvature, and elevation are abbreviated as a, s, c, and e, respectively. Two vegetation indexes and land surface temperature are abbreviated as V2 and lst, respectively. 
For the merging-region scenario (Figure 3f), a comparable accuracy was observed. Overall accuracy and F-measure were over 92\% with an AUC score of approximately $89 \%$. This accuracy confirms the robustness of the proposed method together with the included model inputs, and that it can achieve transferability to other regions even if the model was trained universally, merging all input data to create a globally transferable model setup.

\subsection{External Validations with Optical-Based SCE and Snow Depth Records}

To thoroughly validate the modeled total SCE for the second year, two different external validation approaches were utilized, including validating with optical imagery-based SCE and meteorological snow depth information. These two datasets provide higher spatial resolution than the GSP data.

As shown in Table 2, high-resolution Landsat as well as Sentinel-2 data were chosen based on the criteria of least cloud cover in the shortest temporal distance. The Fmask algorithm [52] was then applied to each scene to derive total SCE (for detailed parameters setting refer to [18]). Based on the resultant total SCE, 10,000 random points were stratified and sampled in both snow-covered and snow-free areas. The confusion matrix and evaluation measurements can thus be calculated as presented in Figure 4. For the two validation months of all five regions, the overall accuracy and F-measure was always consistently over $82 \%$. Only slight over- and under-estimation were observed in the first month of MR and LL, respectively. These evaluations confirm the robustness of the proposed model/data. The months with relatively low accuracy such as month1 of MR (82\%) and month1 of LL (82\%) might be affected by sudden snowfall/snowmelt events occurring during the temporal gap between the SAR and the optical image acquisitions. In study regions with no temporal gaps, the accuracies are generally higher (see month2 of MW (93\%) as well as month1 (90\%) and month2 (91\%) of $\mathrm{AK})$.

To evaluate the improvement of the classification accuracy compared to previous variable combinations [18], a confusion matrix and evaluation measurements using only SAR-based observations and topographical factors (BIP + asce) are also presented in Figure 4. In addition and to summarize the improvement, we used simple rules to judge the performance: (1) if the evaluation measurements of the present study are considerably higher/lower than the previous study, then we marked that case with " $\mathrm{O}$ " $/$ " $\mathrm{X}$ "; if no significant difference is found, it is marked as "-". (2) If the present study eliminates the significant under- or over-estimation shown in the previous study, then we marked that case with another "O"; if the present study shows either under- or over-estimation that is not presented in the previous study, then we marked that case with another " $X$ ". According to these rules, we can summarize the overall improvement level for all ten months. It was found that seven cases showed an improvement while only two cases showed worse performance; therefore, the present study can be considered as a general improvement.

Another validation approach is utilizing the snow depth (SD) information of local meteorological stations. Considering the data availability, only the MR and ZG regions located in the European Alps provide a suitable dataset. The daily SD records of 28 MeteoSwiss stations and 114 stations of the European Climate Assessment and Dataset Project (ECA\&D) [53] were used for validation of the two regions, respectively (for exact locations of the stations refer to [18]). Due to the fact that the locations of meteorological stations are generally at a lower elevation and there is less snow in May (melting season), only SCE of March was validated. The confusion matrix between SAR-based modeled total SCE and SD (if SD is higher than $0 \mathrm{~cm}$, it is defined as snow-covered) is illustrated in Figure 5. Overall, the accuracy was satisfyingly high, i.e., over $82 \%$ in both cases. The validation results of the SCE estimated with the previous variable combination (without vegetation and temperature information) [18] are also shown in Figure 5 and generally present a lower accuracy. This finding agrees with the validation using optical-based SCE as mentioned above, i.e., the present study does demonstrate a modest improvement in classification accuracy. 

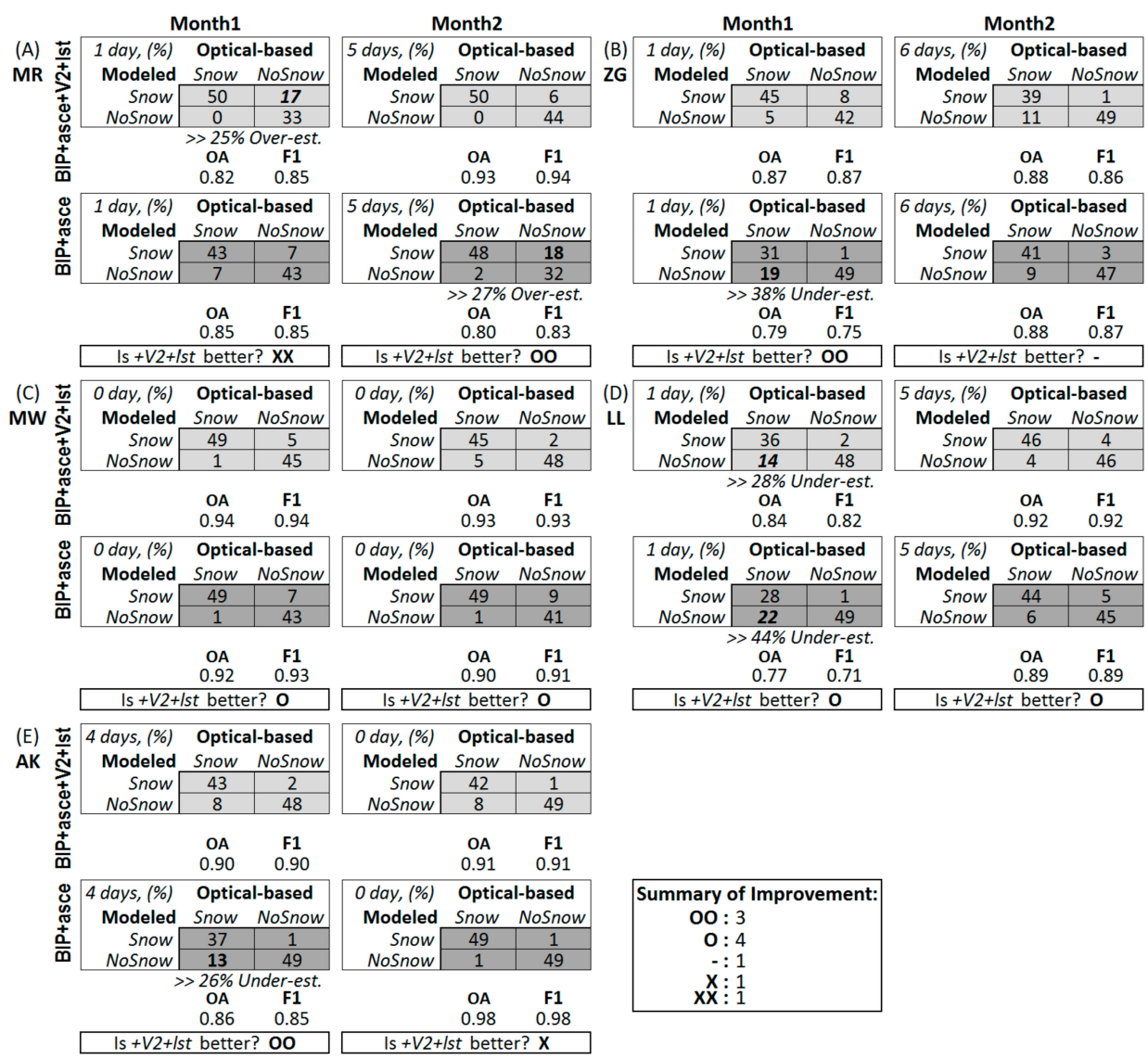

Figure 4. Confusion matrix of the accuracy assessment relying on optical-based snow cover classifications of Landsat and Sentinel-2 for each test site. The assessment includes classifications for months that were trained in the first year (month2) as well as those that were not used in the training of the first year (month1). Overall accuracy (OA) and F1-score are depicted under the respective confusion matrix. The temporal difference (days) between SAR observation image and optical image used for validation is mentioned on the upper-left corner of each confusion matrix. The summary of improvement depicts the improvements achieved by adding vegetation indexes and temperature information: "OO" for major improvement, “ $\mathrm{O}$ ” for slight improvement, "-“ for no change, " $\mathrm{X}$ ” for slight degradation, and " $X X$ " for major degradation. The confusion matrixes marked in light and dark grey colors represent the results of using the present and previous [18] variable combination, respectively.
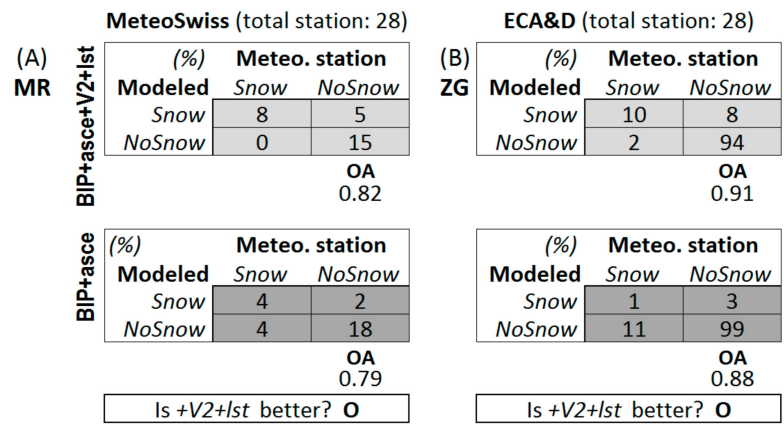

Figure 5. Confusion matrix of the (a) Monte Rosa (MR) and (b) Zugspitze (ZG) regions validated with meteorological snow depth (SD) station data records of MeteoSwiss and the European Climate Assessment and Dataset Project (ECA\&D), respectively. The summary of improvement depicts the improvements achieved by adding vegetation indexes and temperature information: "OO" for major improvement, " $\mathrm{O}$ " for slight improvement, "-- for no change, " $\mathrm{X}$ " for slight degradation, and " $\mathrm{XX}$ " for major degradation. The confusion matrixes marked in light and dark grey colors represent the results of using the present and previous [18] variable combination, respectively. 


\subsection{Holistic Wet and Dry SCE Maps with Reliability Maps}

Via comprehensive internal and external validation based on different data sources as mentioned in 4.1 and 4.2, it is confirmed that all five regions yield credible modeled total SCE. Based on that and to fully utilize the advantages of SAR data, a conventional backscatter-based wet SCE detection approach [17] was also employed. In the present study, the presence of wet snow is only allowed for areas where SCE has been detected by our modelling approach, which helps in removing patchy wet snow caused by salt-and-pepper noise of SAR imagery. By merging both total and wet SCE, dry SCE can therefore be separately depicted as shown in Figure 6. It was clear that the coverage of total/wet SCE is decreasing/increasing in all five regions from month1 to month2 (Table 2) as the melting season starts due to rising temperature.

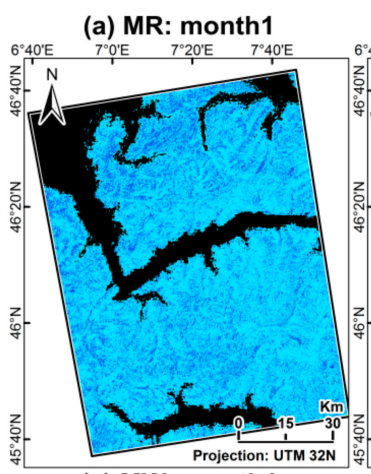

(e) MW: month1

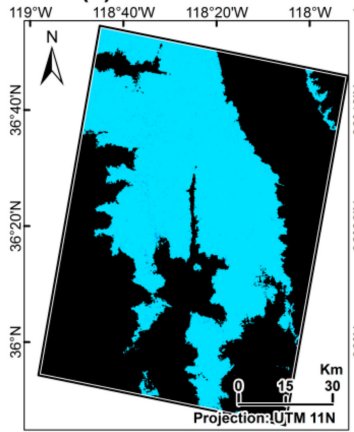

(i) AK: month1

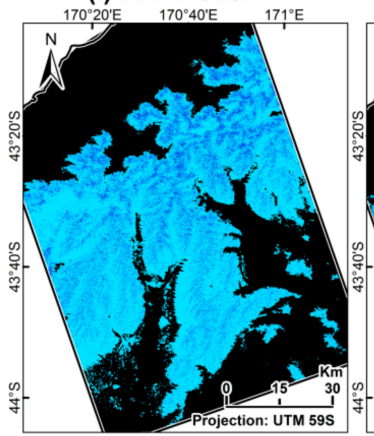

(b) MR: month2

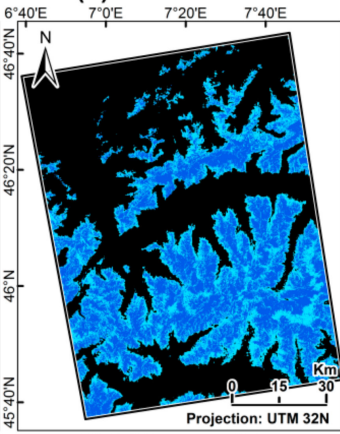

(f) MW: month2

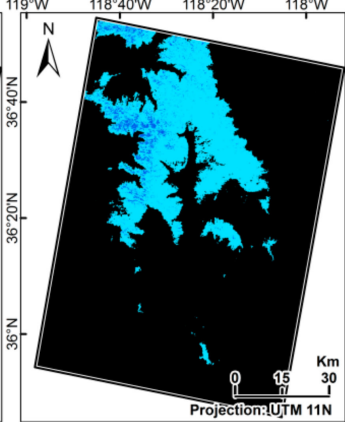

(j) AK: month2

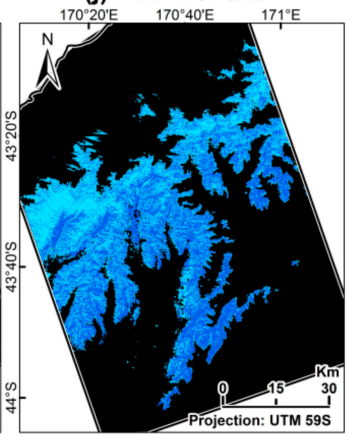

(c) ZG: month1

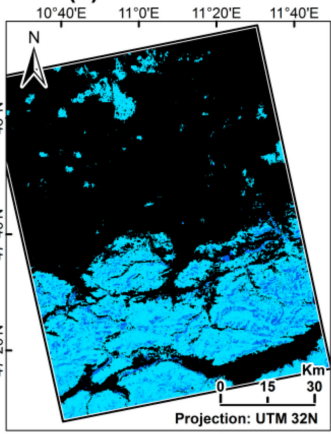

(g) LL: month1

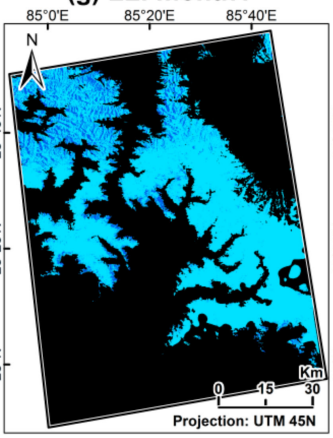

Modeled total SCE

Total SCE

Snowfree

Modeled wet SCE

Wet SCE

Figure 6. Total and wet SCE for two months of each region: (a) Monte Rosa (MR), month 1 (Mar 24, 2018); (b) Monte Rosa, month 2 (May 23, 2018); (c) Zugspitze (ZG), month 1 (Mar 26, 2018); (d) Zugspitze, month 2 (May 13, 2018); (e) Mount Whitney (MW), month 1 (Mar 16, 2018); (f) Mount Whitney, month 2 (May 03, 2018); (g) Landtang Lirung (LL), month 1 (Mar 12, 2018); (h) Landtang Lirung, month 2 (May 11, 2018); (i) Aoraki (AK), month 1 (Jun 30, 2018); (j) Aoraki, month 2 (May 01, 2018).

It should be noted that, currently, there is no comprehensive way to validate the wet SCE in a comparable spatial resolution. Considering the general acceptance of the conventional backscatter threshold-based approach for wet SCE detection in previous studies [16], we did not examine the 
quality of wet SCE in the present study. Nevertheless, as we mentioned in [18], the conventional backscatter threshold-based method is sometimes found to be under-estimating wet SCE especially in patchy snow-covered areas due to the mixture of different scattering characteristics of different ground surfaces.

To overcome the limitation of previous studies, i.e., the lack of reliability information of the produced SCE [16] (which is state-of-the-art in other spaceborne-based cryosphere products [54]), we utilized the advantage of RF to generate a reliability map for the modeled total SCE for each region and each month as illustrated in Figure 7. The reliability for the results is high except for the transition zone (or snow line) between snow-covered and snow-free areas, which is caused by ambiguities in the SAR signal within patchy snow fields (caused by a mix of bare soil, rock, vegetation, and snow) [55-57]. However, as concluded by Malnes et al. [55], this situation can only be compensated by enhancing the spatial resolution of the SAR imagery. Nevertheless, the reliability information along with the modeled total SCE can provide the users a valuable reference about uncertainty for further applications and analysis.

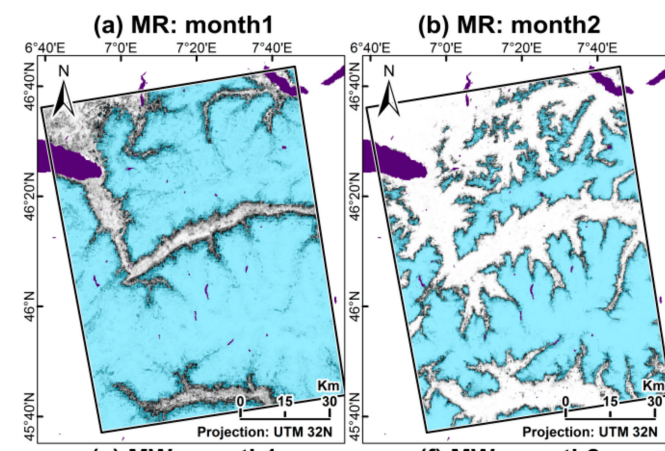

(e) MW: month1

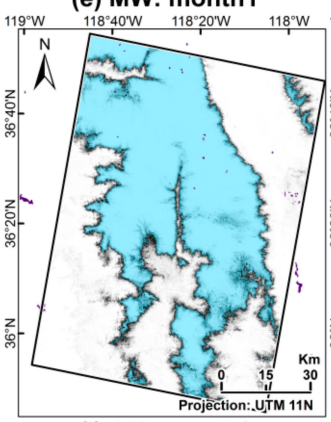

(i) AK: month1

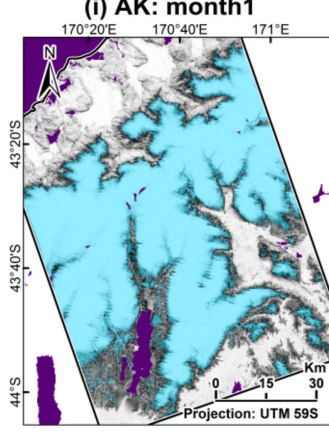

(f) MW: month2

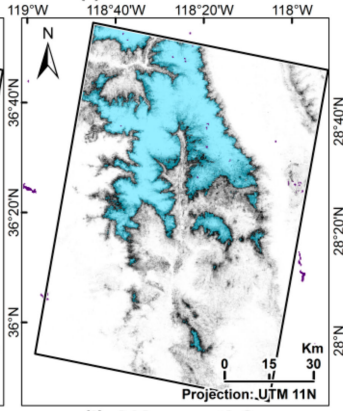

(j) AK: month2

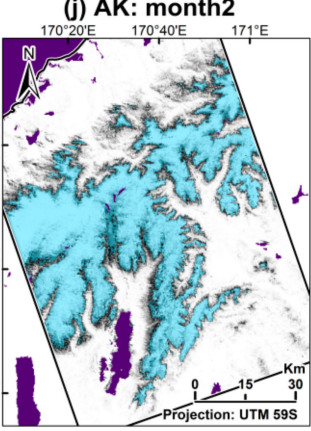

(c) ZG: month1

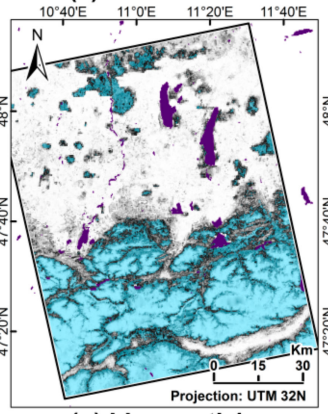

(g) LL: month1

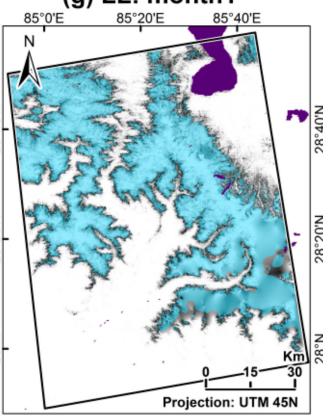

Reliability

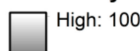

Low: 0

Waterbody

Modeled total SCE (d) ZG: month2

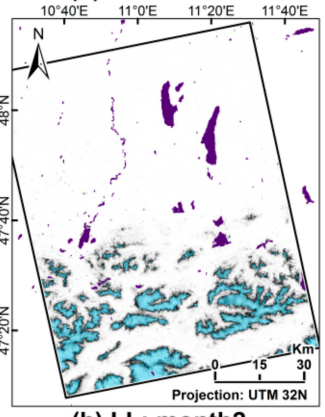

(h) LL: month2

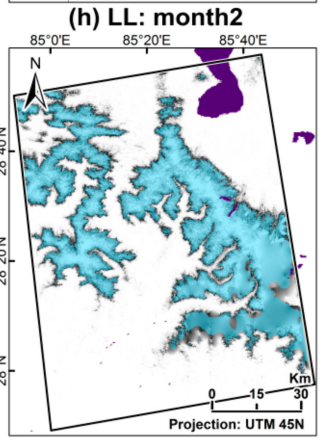

Figure 7. Reliability map with total SCE for two months of each region: (a) Monte Rosa (MR), month 1 (Mar 24, 2018); (b) Monte Rosa, month 2 (May 23, 2018); (c) Zugspitze (ZG), month 1 (Mar 26, 2018); (d) Zugspitze, month 2 (May 13, 2018); (e) Mount Whitney (MW), month 1 (Mar 16, 2018); (f) Mount Whitney, month 2 (May 03, 2018); (g) Landtang Lirung (LL), month 1 (Mar 12, 2018); (h) Landtang Lirung, month 2 (May 11, 2018); (i) Aoraki (AK), month 1 (Jun 30, 2018); (j) Aoraki, month 2 (May 01, 2018). 


\section{Discussion}

\subsection{The Influence of Different Input Variables Combinations to Classification Accuracy}

In the Methodology section, different input combinations were tested, where the "all input included" case yields the highest classification accuracies. To clarify the misunderstanding that it would always have better modeling accuracy when including more inputs, Figure 8 presents the results of employing SAR local incidence angle (LIA) as well as multi-spectral data from high-resolution optical imagery. The results show that neither adding LIA (Figure 8a) nor the six different bands of Sentinel-2 (band 4, 5, 6, 7, 8, and 8A) (Figure 8b) can provide higher accuracy than the previous case, only relying on the SAR-based observations and topographical factors [18]. We presume that this is for two reasons: The terrain correction step in the pre-processing of the SAR observations already eliminates most of the influence of LIA; and the snow-cloud-ice ambiguity within optical imagery largely limits the usable information. Thus, both LIA and Sentinel-2 multi-spectral data were not included in the proposed model.
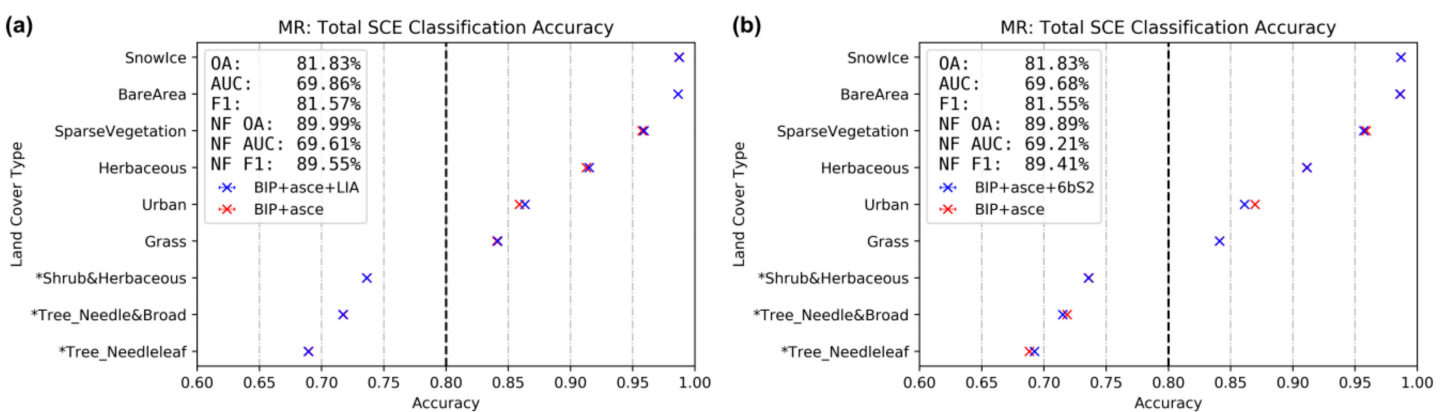

Figure 8. Examination of the accuracy improvement benefits of employing (a) SAR local incidence angle (LIA) and (b) Sentinel-2 multi-bands imagery on the performance of the model for the Monte Rosa (MR) region. Different classification accuracies based on different input combinations are marked in different colors, and the accuracy for each land cover class is marked in the same horizontal axis. SAR-based observations, including backscatter, interferometric SAR (InSAR) coherence, and polarimetric (PolSAR) $\mathrm{H} / \mathrm{A} / \alpha$ parameters are abbreviated as B, I, and P, respectively. Topographical factors, including aspect, slope, curvature, and elevation are abbreviated as a, s, c, and e, respectively. Six bands of Sentinel-2 imagery is abbreviated as $6 \mathrm{bS} 2$.

\subsection{The Influence of Different Land Cover (Vegetation) Types on the Classification Reliability}

To investigate the relationship between vegetation and classification reliability, the reliability of the second year's total SCE was analyzed based on different land cover classes as shown in Figure 9. The land cover classes were categorized to densely, lightly, and non-vegetated land cover classes and colored with deep green, light green, and light blue, respectively. It is obvious that, generally, the reliability is inversely proportional to the density of vegetation, except for the LL region in Himalaya which may differ due to local vegetation characteristics and lower quality of the land cover map caused by more rugged terrain [18]. Namely, densely vegetated classes such as shrubs, broad and needle leaf forest have the poorest reliability; they are followed by mild vegetated classes, including the grass, herbaceous, and sparse vegetation; non-forest classes like bare areas, urban, and snow/ice normally have the highest reliability. This analysis proves previous studies' findings, i.e., stem volume and vegetation height would directly influence the snow detecting abilities of SAR signals [58-60]. However, although these vegetated classes have relatively poor accuracies, most regions still provide an accuracy of over $60 \%$ for $75 \%$ of the pixels (the tail of each box). 
(a)

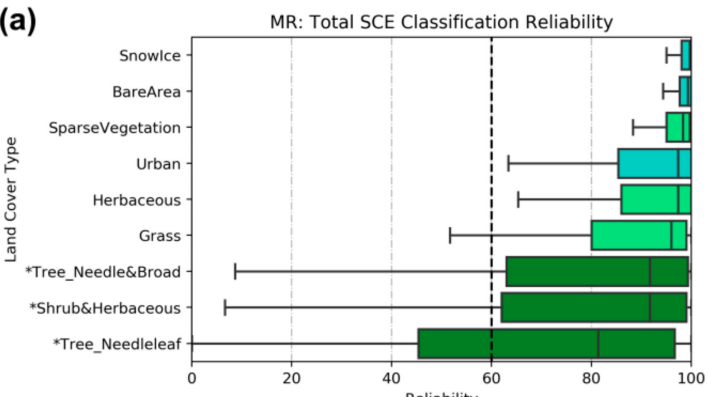

(c)

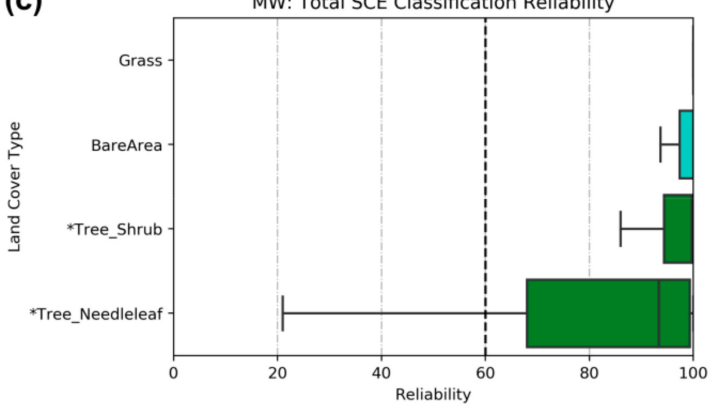

(e)

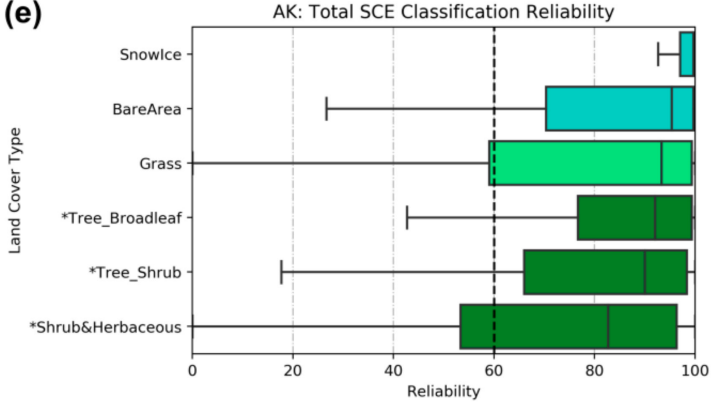

(b)

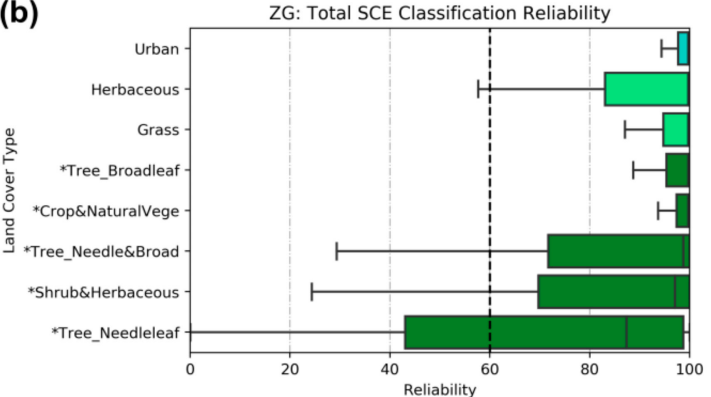

(d)

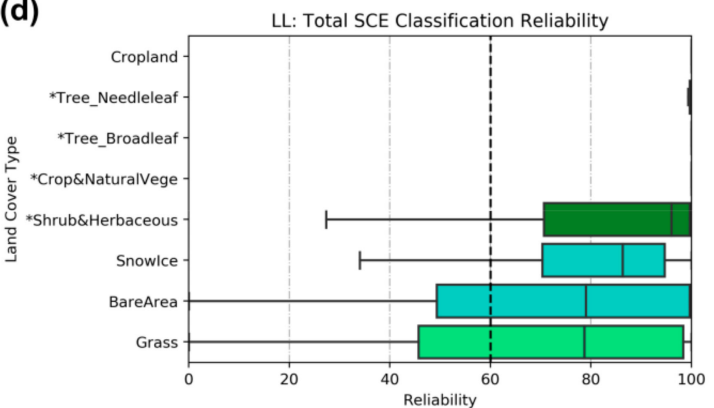

Figure 9. Assessment of the relationship between reliability and land cover class in each region: (a) Monte Rosa (MR); (b) Zugspitze (ZG); (c) Mount Whitney (MW); (d) Landtang Lirung (LL); and (e) Aoraki (AK). Densely, lightly, and non-vegetated land cover classes are colored in deep green, light green, and light blue, respectively.

\subsection{The Heterogeneity between Multispectral-Based Results/Products for Model Training and Validation}

Although the GSP SCE, which is used for training the model, the Landsat/Sentinel-2 Fmask-based SCE, which is used for validation, and the PROBA-V-based vegetation products, which is used for modeling as well, all stem from multispectral sensors, they should not be affected by considerable correlations/biases. These products are calculated with different algorithms/techniques for different purposes, and they are based on several different sensors which acquire the data at varying times. In detail, the total SCE of GSP is calculated by combining both MODIS daily snow cover products (MOD10A1 and MYD10A1) and then applying temporal interpolation, snowline determination with a DEM reference, and a seasonal filter to eliminate the effect of polar darkness and cloud coverage [35]. The GSP is therefore based on an aggregation approach. On the contrary, the Fmask-based Landsat/Sentinel-2 SCE is estimated by executing a water detection relying on the NDVI and the NIR band, cloud detection using thermal bands, and cloud shadow mapping using segmentation of objects' shapes [52]. Fmask can therefore be considered a segmentation approach. Therefore, the way in which total SCE is derived from both approaches is technically different. When it comes to the PROBA-V-based LAI and FVC products, a machine learning-based approach is employed. The products are processed by neural networks with calibrated reflectance inputs, then post-processed with outlier rejection, composition, smoothing, and gap filling [36]. Although derived 
from multispectral data, these three datasets are calculated with different techniques, which prevents a direct correlation/bias between them. Thus, the reliability of the validation can be ensured.

\subsection{Applying the Total SCE Detection Approach to a Wider Spatial Scale-The Whole Alps}

To test the robustness and transferability of the employed model and to examine the practical usability, we applied our approach to the whole Alps for the melting season of 2018 to monitor the total SCE dynamics. By utilizing the same dataset and classification routine as mentioned in Sections 2.2, 2.3 and 3, we can sense the total SCE for the whole Alps from March to May 2018. To emphasize the dynamics of the SCE visually, we only illustrated the results in 24-days interval as shown in Figure 10. It is clear that the pattern of the modeled total SCE matches well with the topography of the mountain ranges. A decrease in total SCE can be observed from March to May as the snow starts to melt due to the increase in temperature. The results indicate that it is practical to depict the total SCE in both dry snow-dominated months (March) as well as wet snow-dominated months (May). This outcome confirms the maturity of our approach and that it is comparable to the conventional optical sensor-based approaches in both spatial and temporal scales.

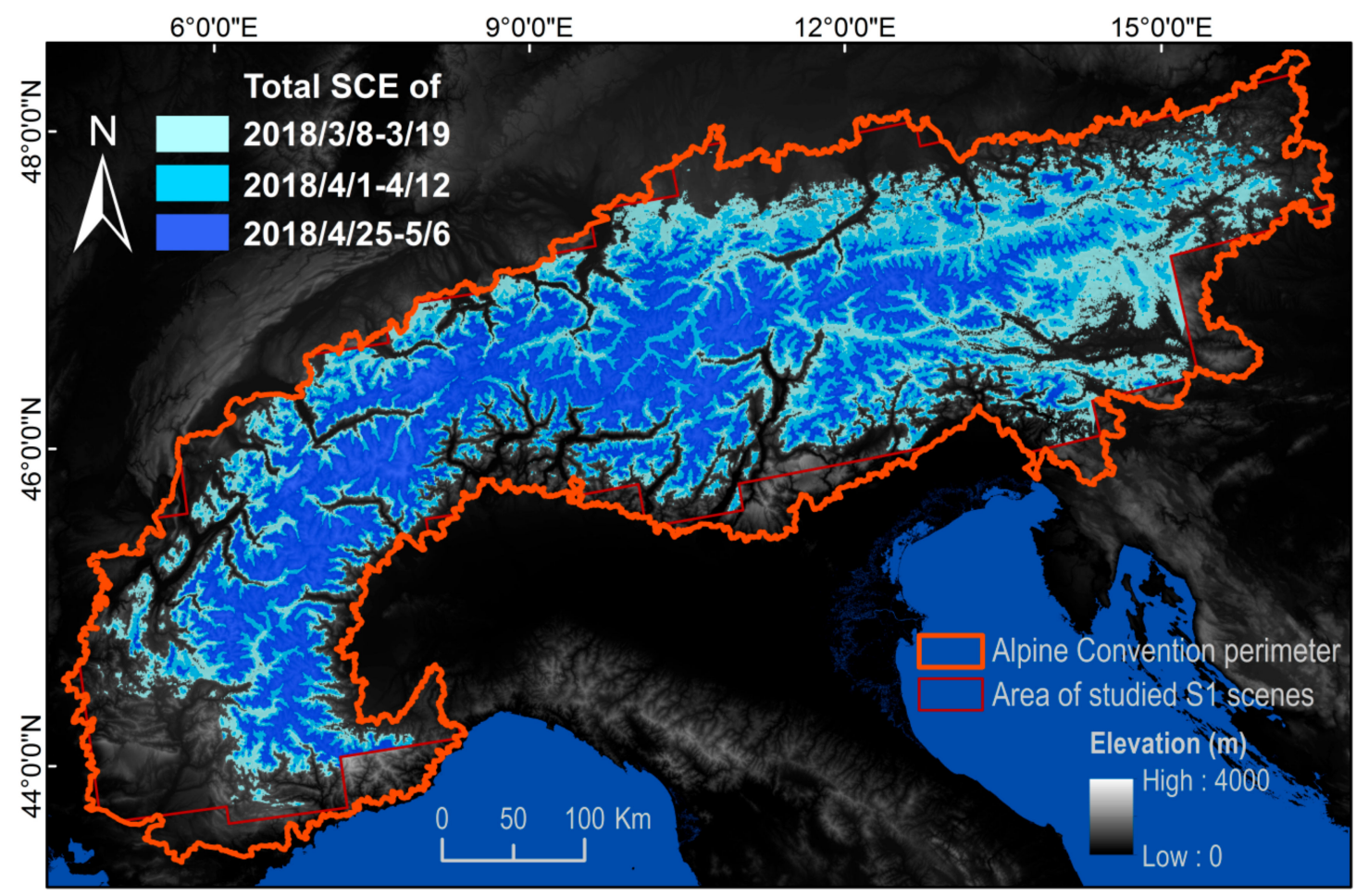

Figure 10. Map of the modeled total SCE for the whole Alps including 8-19 March 2018, 1-12 April 2018, and 25 April-6 May 2018 based on Sentinel-1 SAR observations, topographical factors, vegetation indexes, and temperature information. The total SCE for the different dates is colored differently.

\subsection{Improvements Achieved in This Study and Its Future Potential}

In our previous study [18], we confirmed that by utilizing SAR-based observations (backscatter, InSAR coherence, and PolSAR parameters), topographical factors (elevation, slope, aspect, and curvature), and land cover information, it is possible to map the total SCE with an accuracy of approximately $80 \%$ (calculated based on validation with high resolution optical sensors-based SCE) which was already much higher than previous SAR-based studies [16]. However, this level of accuracy is still generally lower than the conventional optical-based SCE detection approaches. For instance, the MODIS daily snow cover product is confirmed to have an accuracy of approximately $90 \%$ under clear sky conditions [35]. Consequently, to improve the usability of SAR-based results, we added 
two more variable sets which are derived from multi-spectral sensor-based products, including surface temperature (derived from MODIS) and vegetation indexes (derived from PROBA-V), which are commonly employed to map SCE, to enhance the classification accuracy to approximately $90 \%$. These two different input variable combinations and mapping accuracies provide a comprehensive strategy for users to utilize SAR-based observations for total SCE mapping based on data availability. If a region is neither cloud covered nor affected by polar darkness, the multi-spectral sensor-based vegetation and temperature products are trustable. They allow for an RF-based SCE detection with an accuracy of approximately $90 \%$, which is comparable to traditional cloud-free optical-based classification accuracies. If multi-spectral sensors are not available for a region (PROBA-V-based vegetation indexes are influenced by cloud coverage and polar darkness; the MODIS-based temperature product is also affected by cloud coverage), users can still rely on the all-weather sensible, cloud-penetrating SAR-based observations to map total SCE with an accuracy of approximately $80 \%$. Although this accuracy is lower, it largely compensates the void information provided by optical sensors.

However, there is still a limitation for SAR-based SCE detection approaches. According to the Global Observing System for Climate (GCOS), the minimum SCE mapping requirements for the subsequent hydrological and climate applications is $1000 \mathrm{~m}$ spatial resolution and one to five days temporal resolution [61]. Although the current novel spaceborne SAR sensors can easily satisfy the spatial resolution threshold (the spatial resolution of Sentinel-1 is approximately $20 \mathrm{~m}$ ), their revisit time is normally longer than five days even when a multi-satellite constellation is formed (Sentinel-1A and $\mathrm{B}$ can shorten the revisit frequency to six days from original 12 days). Thankfully, the extension of the Sentinel-1 missions has been confirmed, and the launches of Sentinel-1C and D are planed from 2021 onwards [62]. They will compose a more completed constellation system and provide a much denser SAR observation frequency, which will provide a great niche for spaceborne SAR-based SCE mapping approaches.

\section{Conclusions}

Snow cover not only influences many environmental phenomena but also human activities, thus snow monitoring is a critical topic especially because, recently, snow cover extent (SCE) shows a significant decreasing trend globally due to climate change. To overcome the limitations of conventional optical-based approaches, including cloud coverage and polar darkness, the utilization of spaceborne SAR is explored in the present study. Compared to our previous paper [18], which only utilized SAR-based observations (backscatter, InSAR coherence, and PolSAR parameters) and topographical factors (elevation, slope, aspect, and curvature), the value of employing vegetation indexes (LAI and FVC) as well as land surface temperature (LST) derived from the PROBA-V satellite and MODIS sensors, respectively, has been examined. It was confirmed that the overall accuracy, F-measure, and AUC score can be enhanced from 80,80 , and $70 \%$ to approximately 90,90 , and $80 \%$ for all the five study areas located in different mountain ranges, continents, and hemispheres.

Based on the satisfying accuracy among all validation trials with different data sources, the transferability of the method and data proposed in the present study was also ensured. Moreover, the newly generated reliability maps along with the modeled total SCE provides a potential for evaluating the uncertainty for further application and analysis. For instance, a relationship between lower modeled reliability with densely vegetated land cover classes was confirmed and discussed. Additionally, to examine the assumption of "more inputs can always yield better classification accuracy," both the SAR's local incidence angle as well as multi-band imagery from the high-resolution optical sensor were also tested, which did not improve the accuracy significantly. Eventually, we successfully applied our approach to map the total SCE dynamics for the whole Alps during the melting season of 2018, which confirms the transferability and applicability of the approach.

Most important of all, based on the present study, we provide an alternative approach to map the total SCE (wet + dry snow) in the scenario that multi-spectral auxiliary products (LAI, FVC, LST) are trustable. Together with our previous paper [18] only relying on SAR-based observations and static 
topographical factors, these two different input variable settings provide users a package to achieve satisfactory total SCE mapping accuracies based on different data availability. It largely compensates the traditional limitation of optical-based SCE detection approaches and also provides extra wet SCE information which cannot be detected by optical sensors.

Author Contributions: Conceptualization, Y.-L.S.T., A.D. and C.K.; Methodology, Y.-L.S.T.; Validation, Y.-L.S.T.; Writing, Y.-L.S.T.; Review and Editing, A.D., C.K., and N.O.; Supervision, A.D., C.K., and N.O.

Funding: This research received no external funding.

Acknowledgments: Support by the German Academic Exchange Service (DAAD) fellowship to Ya-Lun S. Tsai is gratefully acknowledged. The authors thank the providers of the meteorological data used in this article, including MeteoSwiss (the Swiss Federal Office of Meteorology and Climatology) as well as the ECA\&D project (Data and metadata available at http://eca.knmi.nl).

Conflicts of Interest: The authors declare no conflict of interest.

\section{References}

1. Najafi, M.R.; Zwiers, F.W.; Gillett, N.P. Attribution of the spring snow cover extent decline in the Northern Hemisphere, Eurasia and North America to anthropogenic influence. Clim. Chang. 2016, 136, 71-586. [CrossRef]

2. Hori, M.; Sugiura, K.; Kobayashi, K.; Aoki, T.; Tanikawa, T.; Kuchiki, K.; Niwano, M.; Enomoto, H. A 38-year (1978-2015) Northern Hemisphere daily snow cover extent product derived using consistent objective criteria from satellite-borne optical sensors. Remote Sens. Environ. 2017, 191, 402-418. [CrossRef]

3. Pachauri, R.K.; Allen, M.R.; Barros, V.R.; Broome, J.; Cramer, W.; Christ, R.; Church, J.A.; Clarke, L.; Dahe, Q.; Dasgupta, P. Climate Change 2014: Synthesis Report. Contribution of Working Groups I, II and III to the Fifth Assessment Report of the Intergovernmental Panel on Climate Change; IPCC: Geneva, Switzerland, 2014.

4. Hoegh-Guldberg, O.; Jacob, D.; Taylor, M.; Bindi, M.; Brown, S.; Camilloni, I.; Diedhiou, A.; Djalante, R.; Ebi, K.; Engelbrecht, F. Impacts of $1.5^{\circ} \mathrm{C}$ Global Warming On Natural And Human Systems; International Institute for Applied Systems Analysis (IIASA): Laxenburg, Austria, 2018.

5. Huss, M.; Bookhagen, B.; Huggel, C.; Jacobsen, D.; Bradley, R.S.; Clague, J.J.; Vuille, M.; Buytaert, W.; Cayan, D.R.; Greenwood, G. Toward mountains without permanent snow and ice. Earth's Future 2017, 5, 418-435. [CrossRef]

6. Singh, G.; Venkataraman, G.; Yamaguchi, Y.; Park, S.E. Capability Assessment of Fully Polarimetric ALOS-PALSAR Data for Discriminating Wet Snow From Other Scattering Types in Mountainous Regions. IEEE Trans. Geosci. Remote Sens. 2014, 52, 1177-1196. [CrossRef]

7. Schöber, J.; Schneider, K.; Helfricht, K.; Schattan, P.; Achleitner, S.; Schöberl, F.; Kirnbauer, R. Snow cover characteristics in a glacierized catchment in the Tyrolean Alps-Improved spatially distributed modelling by usage of Lidar data. J. Hydrol. 2014, 519, 3492-3510. [CrossRef]

8. Barnett, T.P.; Adam, J.C.; Lettenmaier, D.P. Potential impacts of a warming climate on water availability in snow-dominated regions. Nature 2005, 438, 303. [CrossRef] [PubMed]

9. Beniston, M.; Farinotti, D.; Stoffel, M.; Andreassen, L.M.; Coppola, E.; Eckert, N.; Fantini, A.; Giacona, F.; Hauck, C.; Huss, M. The European mountain cryosphere: A review of its current state, trends, and future challenges. Cryosphere 2018, 12, 759. [CrossRef]

10. Pogliotti, P.; Guglielmin, M.; Cremonese, E.; di Cella, U.M.; Filippa, G.; Pellet, C.; Hauck, C. Warming permafrost and active layer variability at Cime Bianche, Western European Alps. Cryosphere 2015, 9, 647-661. [CrossRef]

11. Yang, Y.; Leppäranta, M.; Cheng, B.; Li, Z. Numerical modelling of snow and ice thicknesses in Lake Vanajavesi, Finland. Tellus A Dyn. Meteorol. Oceanogr. 2012, 64, 17202. [CrossRef]

12. Riggs, G.A.; Hall, D.K. MODIS Snow Products Collection 6 User Guide; National Snow and Ice Data Center: Boulder, CO, USA, 2015.

13. Solberg, R.; Wangensteen, B.; Metsämäki, S.; Nagler, T.; Sandner, R.; Rott, H.; Wiesmann, A.; Luojus, K.; Kangwa, M.; Pulliainen, J. GlobSnow Snow Extent Product Guide Product Version 1.0; European Space Angency: Helsinki, Finland, 2010. 
14. Bartsch, A.; Jansa, J.; Schöner, M.; Wagner, W. Monitoring of Spring Snowmelt with Envisat ASAR WS in the Eastern Alps by Combination of Ascending and Descending Orbits; Vienna University of Technology: Vienna, Austria, 2007.

15. Macander, M.J.; Swingley, C.S.; Joly, K.; Raynolds, M.K. Landsat-based snow persistence map for northwest Alaska. Remote Sens. Environ. 2015, 163, 23-31. [CrossRef]

16. Tsai, Y.-L.S.; Dietz, A.; Oppelt, N.; Kuenzer, C. Remote Sensing of Snow Cover Using Spaceborne SAR: A Review. Remote Sens. 2019, 11, 1456. [CrossRef]

17. Nagler, T.; Rott, H. Retrieval of wet snow by means of multitemporal SAR data. IEEE Trans. Geosci. Remote Sens. 2000, 38, 754-765. [CrossRef]

18. Tsai, Y.L.S.; Dietz, A.; Oppelt, N.; Kuenzer, C. Wet and Dry Snow Detection Using Sentinel-1 SAR Data for Mountainous Areas with a Machine Learning Technique. Remote Sens. 2019, 11, 895. [CrossRef]

19. Snehmani, M.K.S.; Gupta, R.D.; Bhardwaj, A.; Joshi, P.K. Remote sensing of mountain snow using active microwave sensors: A review. Geocart. Intern. 2015, 30, 1-27. [CrossRef]

20. Cloude, S.R.; Pottier, E. A review of target decomposition theorems in radar polarimetry. IEEE Trans. Geosci. Remote Sens. 1996, 34, 498-518. [CrossRef]

21. Huang, L.; Li, Z.; Tian, B.S.; Chen, Q.; Liu, J.L.; Zhang, R. Classification and snow line detection for glacial areas using the polarimetric SAR image. Remote Sens. Environ. 2011, 115, 1721-1732. [CrossRef]

22. Longepe, N.; Shimada, M.; Allain, S.; Pottier, E. Capabilities of full-polarimetric PALSAR/ALOS for snow extent mapping. In Proceedings of the IGARSS 2008-2008 IEEE International Geoscience and Remote Sensing Symposium, Boston, MA, USA, 7-11 July 2008.

23. He, G.; Feng, X.; Xiao, P.; Xia, Z.; Wang, Z.; Chen, H.; Li, H.; Guo, J. Dry and Wet Snow Cover Mapping in Mountain Areas Using SAR and Optical Remote Sensing Data. IEEE J. Sel. Top. Appl. Earth Obs. Remote Sens. 2017, 10, 2575-2588. [CrossRef]

24. Pal, M. Random forest classifier for remote sensing classification. Int. J. Remote Sens. 2005, 26, $217-222$. [CrossRef]

25. Adam, E.; Mutanga, O.; Odindi, J.; Abdel-Rahman, E.M. Land-use/cover classification in a heterogeneous coastal landscape using RapidEye imagery: Evaluating the performance of random forest and support vector machines classifiers. Int. J. Remote Sens. 2014, 35, 3440-3458. [CrossRef]

26. Rodriguez-Galiano, V.; Sanchez-Castillo, M.; Chica-Olmo, M.; Chica-Rivas, M. Machine learning predictive models for mineral prospectivity: An evaluation of neural networks, random forest, regression trees and support vector machines. Ore Geol. Rev. 2015, 71, 804-818. [CrossRef]

27. Luojus, K.P.; Pulliainen, J.T.; Metsämäki, S.J.; Hallikainen, M.T. Snow-Covered Area Estimation Using Satellite Radar Wide-Swath Images. IEEE Trans. Geosci. Remote Sens. 2007, 45, 978-989. [CrossRef]

28. Dedieu, J.P.; de Farias, G.B.; Castaings, T.; Allain-Bailhache, S.; Pottier, E.; Durand, Y.; Bernier, M. Interpretation of a RADARSAT-2 fully polarimetric time-series for snow cover studies in an Alpine context-first results. Can. J. Remote Sens. 2012, 38, 336-351. [CrossRef]

29. Hongxing, L.; Lei, W.; Jezek, K.C. Automated delineation of dry and melt snow zones in Antarctica using active and passive microwave observations from space. IEEE Trans. Geosci. Remote Sens. 2006, 44, 2152-2163. [CrossRef]

30. Zhou, C.; Zheng, L. Mapping Radar Glacier Zones and Dry Snow Line in the Antarctic Peninsula Using Sentinel-1 Images. Remote Sens. 2017, 9, 1171. [CrossRef]

31. Tedesco, M. Snowmelt detection over the Greenland ice sheet from SSM/I brightness temperature daily variations. Geophys. Res. Lett. 2007, 34, 2. [CrossRef]

32. Pulliainen, J.T. Investigation on the Backscattering Properties of Finnish Boreal Forests at C-and X-band: A Semi-Empirical Modeling Approach. Ph.D. Thesis, Helsinki University of Technology, Espoo, Finland, 1994.

33. Pulliainen, J.T.; Heiska, K.; Hyyppa, J.; Hallikainen, M.T. Backscattering properties of boreal forests at the C-and X-bands. IEEE Trans. Geosci. Remote Sens. 1994, 32, 1041-1050. [CrossRef]

34. Park, S.-E.; Yamaguchi, Y.; Singh, G.; Yamaguchi, S.; Whitaker, A.C. Polarimetric SAR Response of Snow-Covered Area Observed by Multi-Temporal ALOS PALSAR Fully Polarimetric Mode. IEEE Trans. Geosci. Remote Sens. 2014, 52, 329-340. [CrossRef]

35. Dietz, A.J.; Kuenzer, C.; Dech, S. Global SnowPack: A new set of snow cover parameters for studying status and dynamics of the planetary snow cover extent. Remote Sens. Lett. 2015, 6, 844-853. [CrossRef] 
36. Baret, F.; Weiss, M.; Verger, A.; Smets, B. Atbd For Lai, Fapar And Fcover From Proba-V Products At 300m Resolution (Geov3); INRA: Paris, France, 2016.

37. Wan, Z.; Hook, S.; Hulley, G. MOD11A1 MODIS/Terra Land Surface Temperature/Emmissivity Daily L3 Global 1 km SIN Grid V006; NASA EOSDIS LP DAAD; NASA: Washington, DC, USA, 2015.

38. Wan, Z. Collection-5 Modis Land Surface Temperature Products Users' Guide; ICESS, University of California: Santa Barbara, CA, USA, 2007.

39. Mao, K.; Ma, Y.; Tan, X.L.; Shen, X.; Liu, G.; Li, Z.; Chen, J.; Xia, L. Global surface temperature change analysis based on MODIS data in recent twelve years. Adv. Space Res. 2017, 59, 503-512. [CrossRef]

40. Wan, Z. New refinements and validation of the MODIS land-surface temperature/emissivity products. Remote Sens. Environ. 2008, 112, 59-74. [CrossRef]

41. Sazonau, V. Implementation and Evaluation of a Random Forest Machine Learning Algorithm; University of Manchester: Manchester, UK, 2012.

42. Ali, J.; Khan, R.; Ahmad, N.; Maqsood, I. Random forests and decision trees. Int. J. Comput. Sci. Issues (Ijcsi) 2012, 9, 272.

43. Belgiu, M.; Drăguț, L. Random forest in remote sensing: A review of applications and future directions. Isprs J. Photogramm. Remote Sens. 2016, 114, 24-31. [CrossRef]

44. Lewis, D.D.; Gale, W.A. A sequential algorithm for training text classifiers. In Proceedings of the 17th Annual International ACM SIGIR Conference on Research and Development in Information Retrieval, Dublin, Ireland, 3-6 July 1994.

45. Fawcett, T. An introduction to ROC analysis. Pattern Recognit. Lett. 2006, 27, 861-874. [CrossRef]

46. Sokolova, M.; Japkowicz, N.; Szpakowicz, S. Beyond accuracy, F-score and ROC: A family of discriminant measures for performance evaluation. In Proceedings of the Australasian Joint Conference on Artificial Intelligence, Hobart, Australia, 4-8 December 2006.

47. Ferri, C.; Hernández-Orallo, J.; Modroiu, R. An experimental comparison of performance measures for classification. Pattern Recognition Lett. 2009, 30, 27-38. [CrossRef]

48. Jagt, B.J.V.; Durand, M.T.; Margulis, S.A.; Kim, E.J.; Molotch, N.P. On the characterization of vegetation transmissivity using LAI for application in passive microwave remote sensing of snowpack. Remote Sens. Environ. 2015, 156, 310-321. [CrossRef]

49. Strobl, C.; Boulesteix, A.L.; Kneib, T.; Augustin, T.; Zeileis, A. Conditional variable importance for random forests. BMC Bioinform. 2008, 9, 307. [CrossRef] [PubMed]

50. Strobl, C.; Boulesteix, A.L.; Zeileis, A.; Hothorn, T. Bias in random forest variable importance measures: Illustrations, sources and a solution. BMC Bioinform. 2007, 8, 25. [CrossRef]

51. Luojus, K.P.; Pulliainen, J.T.; Metsämäki, S.J.; Hallikainen, M.T. Accuracy assessment of SAR data-based snow-covered area estimation method. IEEE Trans. Geosci. Remote Sens. 2006, 44, 277-287. [CrossRef]

52. Qiu, S.; He, B.; Zhu, Z.; Liao, Z.; Quan, X. Improving Fmask cloud and cloud shadow detection in mountainous area for Landsats 4-8 images. Remote Sens. Environ. 2017, 199, 107-119. [CrossRef]

53. Tank, A.K.; Wijngaard, J.; Können, G.; Böhm, R.; Demarée, G.; Gocheva, A.; Mileta, M.; Pashiardis, S.; Hejkrlik, L.; Kern-Hansen, C. Daily dataset of 20th-century surface air temperature and precipitation series for the European Climate Assessment. Int. J. Clim. 2002, 22, 1441-1453. [CrossRef]

54. Tsai, Y.; Lin, S.; Kim, J. Tracking Greenland Russell Glacier Movements Using Pixel-offset Method. J. Photogramm. Remote Sens. 2018, 23, 173-189.

55. Malnes, E.; Storvold, R.; Lauknes, I.; Pettinato, S. Multi-polarisation measurements of snow signatures with air-and satelliteborne SAR. Earsel Eproceedings 2006, 5, 111.

56. Pettinato, S.; Malnes, E.; Haarpaintner, J. Snow cover maps with satellite borne SAR: A new approach in harmony with fractional optical SCA retrieval algorithms. In Proceedings of the IEEE International Geoscience and Remote Sensing Symposium, Denver, CO, USA, 31 July-4 August 2006.

57. Storvold, R.; Malnes, E.; Larsen, Y.; Høgda, K.; Hamran, S.; Mueller, K.; Langley, K. SAR remote sensing of snow parameters in norwegian areas-Current status and future perspective. J. Electromagn. Waves Appl. 2006, 20, 1751-1759. [CrossRef]

58. Löw, A.; Ludwig, R.; Mauser, W. Land use dependent snow cover retrieval using multitemporal, multisensoral SAR-images to drive operational flood forecasting models. In Proceedings of the of EARSeL-LISSIG-Workshop Observing our Cryosphere from Space, Bern, Switzerland, 11-13 March 2002. 
59. Schellenberger, T.; Ventura, B.; Zebisch, M.; Notarnicola, C. Wet Snow Cover Mapping Algorithm Based on Multitemporal COSMO-SkyMed X-Band SAR Images. IEEE J. Sel. Top. Appl. Earth Obs. Remote Sens. 2012, 5 , 1045-1053. [CrossRef]

60. Duguay, Y.; Bernier, M. The use of RADARSAT-2 and TerraSAR-X data for the evaluation of snow characteristics in subarctic regions. In Proceedings of the 2012 IEEE International Geoscience and Remote Sensing Symposium (IGARSS), Munich, Germany, 22-27 July 2012.

61. Key, J.; Drinkwater, M.; Ukita, J. IGOS cryosphere theme report. WMO/TD 2007, 1405, 100.

62. Torres, R.; Lokas, S.; di Cosimo, G.; Geudtner, D.; Bibby, D. Sentinel 1 evolution: Sentinel-1C and-1D models. In Proceedings of the 2017 IEEE International Geoscience and Remote Sensing Symposium (IGARSS), Fort Worth, TX, USA, 23-28 July 2017.

C 2019 by the authors. Licensee MDPI, Basel, Switzerland. This article is an open access article distributed under the terms and conditions of the Creative Commons Attribution (CC BY) license (http://creativecommons.org/licenses/by/4.0/). 